\title{
Spatial heterogeneity and host repression in fig-fig wasp mutualism
}

\author{
WANG RuiWu ${ }^{1 *}$, WEN XiaoLan ${ }^{1}$, CHEN Chun ${ }^{1}$, SHI Lei ${ }^{2} \&$ COMPTON Stephen G. ${ }^{3,4}$ \\ ${ }^{1}$ State Key Laboratory of Genetic Resources and Evolution, Kunming Institute of Zoology, Chinese Academy of Sciences, Kunming 650223, \\ China; \\ ${ }^{2}$ Statistics and Mathematics College, Yunnan University of Finance and Economics, Kunming 650221, China; \\ ${ }^{3}$ Department of Zoology and Entomology, Rhodes University, Grahamstown 6140, South Africa; \\ ${ }^{4}$ School of Biology, University of Leeds, Leeds, LS2 9JT, UK
}

Received December 31, 2014; accepted March 3, 2015; published online April 10, 2015

\begin{abstract}
It is generally believed that physical heterogeneity in common resource or evolutionary restraint can sufficiently prevent direct conflict between host and symbionts in mutualism systems. Our data on fig/fig wasp reciprocal mutualism (Ficus racemosa), however, show that structural barriers of female flowers or genetic constraints of pollinators previously hypothesized exist, but cannot sufficiently maintain the mutualism stability. The results show that a positive relationship between seed and wasp production could be maintained in warm season, which might be because of density dependence restraint among foundresses and their low oviposition and pollination efficiency, keeping common resource (female flowers) utilization unsaturated. Whilst, a negative correlation between wasp offspring and viable seed production was also observed in cold season, which might be that the increased oviposition and pollination efficiency maximized the common resource utilization. The fitness trade-off between fig and pollinator wasps is greatly affected by environmental or ecological variations. The local stability might result from temporal low exploitation efficiency of pollinators together with interference competition among pollinators. We suggest that host repression through the active regulation of bract closure, which can create interference competition among the foundresses and prevent extra more foundresses sequential entry in fruit cavities, would help the figs avoiding the cost of over-exploitation. This essentially takes the same role as sanctioning of cheating or competitive behaviors.
\end{abstract}

Agaonidae, cooperation, conflict, co-evolution, repression, mutualism, density dependence

Citation: Wang RW, Wen XL, Chen C, Shi L, Compton SG. Spatial heterogeneity and host repression in fig-fig wasp mutualism. Sci China Life Sci, 2015, 58: 492-500, doi: 10.1007/s11427-015-4848-x

Figs are the characteristic inflorescences of Ficus species (Moraceae) that are pollinated exclusively by host specific fig wasps (Hymenoptera: Agaonidae). The fig tree/fig wasp mutualism is one of the best documented inter-specific cooperation systems where conflicts of interest between the participants are evident. In monoecious fig trees, each fig provides some female flowers for the development of fig wasp offspring, while most of the remainder are pollinated to produce seeds. However, because both fig tree and

*Corresponding author (email: wangrw@ mail.kiz.ac.cn) agaonid fitness depend on the same resource, namely female fig flowers, a conflict for this resource must exist, even though female agaonids contribute to the fitness of the plant, by transporting its pollen [1-5]. Why fig wasps do not evolve to over-exploit female flowers at the expense of viable seeds and thereby undermine the mutualism?

Several hypotheses have attempted to explain why fig wasps do not over-exploit the female flowers. An early hypothesis proposed that pollinators typically have short ovipositors that cannot lay eggs in seeds of long-styled female flowers, and these flowers therefore escape utilization by 
wasp larvae [6-9]. However, many studies have shown that style length distribution in monoecious figs is not bimodal, and there is no separation into long and short styled flowers $[10,11]$. Furthermore, female agaonids typically have ovipositors of sufficient length to oviposit in most of the flowers [10-12]. Clearly the 'short-ovipositor-length' hypothesis fails to provide an explanation [13]. Longer styled flowers are nonetheless more likely to produce seeds, while shorter styled flowers are more likely to produce agaonid offspring.

West and Herre [14] found that some of the ovaries of figs are free not only of agaonids, but also of non-pollinator fig wasps. They suggested the 'unbeatable seed hypothesis, i.e., that some ovaries are unsuitable for the development of any wasps and only can develop into viable seeds. However, because many non-pollinators target ovaries already containing progeny of the pollinator wasps [14-16], it may be that un-exploited flowers are those that were avoided by pollinator wasps and therefore remained unexploited by the non-pollinators too. Furthermore, the unbeatable seed hypothesis assumes that some ovaries are not accessible to oviposition because of barriers that can prevent either oviposition or development of wasp larvae. If so, agaonid offspring numbers should plateau at a level below the number of physically accessible ovaries. However, experimental data show that the plateau for wasp offspring number can be close to the total number of accessible ovaries when the number of foundresses is experimentally increased [11].

The 'enemy-free space' hypothesis suggests that if larvae developing towards the periphery of a fig are more likely to be attacked by parasitoid fig wasps (these belong to other families of Chalicoidea), then selection will favor individuals that restrict their egg laying to shorter styled flowers [17]. However, not all figs display spatial structuring of fig wasp species [18] and the less-preferred long-styled flowers should still be exploited when there are no more short-styled female flowers available. The issue is made more complex by the differential pedicel growth of ovaries occupied by some fig wasps (meaning that their position relative to the periphery changes over time) [19]. Evidence is nonetheless available that shorter styled flowers are used preferentially by agaonids [18], but this may also reflect selection to oviposit in shorter styled flowers simply because it is easier, and quicker, to do so.

The 'insufficient eggs hypothesis' postulates that insufficient numbers of foundresses enter figs to saturate the utilization of flowers with egg oviposition. Such limitation has been documented in several African Ficus species [11,20]. However, many Ficus species receive multiple foundresses, and foundress numbers can vary dramatically between species [15,21]. Density dependent interference competition between the foundresses together with high temperature may be responsible for per capita reductions in the numbers of offspring in figs entered by increasing numbers of females [16,22]. However, this hypothesis does not efficiently explain why direct conflict could be observed in both warm and cold seasons occasionally [22], and it also does not make clear on if the interference competition and high temperature could exclusively explain the fig-fig wasp mutualism stability.

In this study, we examine whether the above suggested mechanisms are sufficient to prevent conflict between Ficus racemosa and its fig wasp pollinator. We then try to integrate 'insufficient eggs hypothesis' with the mechanisms of interference competition and high temperature to explain stability of mutualism interaction stability between figs and fig wasps. We examined factors that may determine the fate of female flowers inside figs - whether they become seeds, support development of pollinator larvae, or fail to do either? We tested (i) whether long styles make some ovules physically inaccessible to pollinators, thereby preventing oviposition and reserving them for seed production; (ii) whether varying temperatures result in seasonal variation in relative seed and wasp production, pollinator lifespan, pollination efficiency egg deposition, and ostiole closure rates [15,21]; (iii) the extent to which foundress abundance can affect offspring and seed production; (iv) whether the amount of the common resource available (number of vacant female flowers and total number of female flowers per fig) can affect the number of viable seeds and wasp offspring produced. These factors interact in complex ways to determine the production of viable seeds and wasp offspring $[1,2,10-12,23]$ and we conclude by highlighting that different conclusions can be reached, depending on the season when a study takes place.

\section{Materials and methods}

\subsection{Study species}

Ficus racemosa Linn. (Subgenus Sycomorus) is distributed from India to Australia [24]. Ficus racemosa is a large tree that can reach $30 \mathrm{~m}$ high and bears cauliflorous fruits synchronously within the tree in very large numbers. It grows mainly in moist valleys or along rivers. Trees of $F$. racemosa usually grow in groups of five to 10. Ficusracemosa is pollinated by the wasp species Ceratoslen fusciceps Mayr (Agaonidae). The foundress number per receptive fruit of $F$. racemosa usually ranges from 1 to 30 , but can sometimes reach more than 70 [25]. There is no endangered or protected species involved in this study.

\subsection{Study site}

The study was carried out in and near to the Xishuangbanna Tropical Botanic Garden (XTBG) in Yunnan province, China $\left(21^{\circ} 41^{\prime} \mathrm{N}, 101^{\circ} 25^{\prime} \mathrm{E}\right)$ and no specific permissions were required for research in this location. This garden is approximately $600 \mathrm{~m}$ above sea level and has a monsoonal climate. The rainy and dry seasons last from May to Octo- 
ber and from November to April, respectively. Mean annual precipitation is $1,557 \mathrm{~mm}$ with about $80 \%$ occurring during the rainy season [26]. The mean annual temperature is $21^{\circ} \mathrm{C}$, but the temperature between November to February is much lower than in other months $[16,26]$.

\subsection{Style and ovipositor lengths}

Pollinator fig wasps usually deposit their eggs into the ovules of fig flowers by inserting their ovipositors through their stigmas and styles [27]. The style and pedicel lengths of the flowers inside monoecious figs vary greatly, and if a flower has styles that are longer than the fig wasp's ovipositor then no egg can be laid. We compared the ovipositor lengths of $C$. fusciceps with the range of style lengths inside figs of $F$. racemosa to assess the proportion of ovules that were accessible to the fig wasps that had entered the figs. Single receptive fig containing live foundresses were collected from five trees between April and June. From each fig we randomly chose about 60 female flowers to measure style lengths (from the top of the ovary to the base of the stigma) and pedicel lengths. The ovipositor lengths of the pollinators inside the figs were also recorded, from their point of attachment to the basal plates to the tips, after separating off the sheaths $[11,12]$.

On three of trees we selected 10 figs, and enclosed them in nylon gauze to exclude subsequent oviposition by non-pollinating fig wasps (NPFW). When the figs matured we measured the style and pedicel lengths of about 60 randomly-selected galls that had supported pollinator offspring development and 70 seeds in each fig. Receptive flowers and ovipositor lengths were recorded from June to July. The mature figs were sampled between November and January.

\subsection{Numbers of viable seeds and pollinator offspring}

In order to monitor trade-offs between seeds and pollinator offspring, we allowed pollinators to naturally enter receptive figs on the same tree and then enclosed the figs in nylon gauze bags to exclude non-pollinators $(N=65$ in the warm season and $N=75$ in the cold season). Collecting from the same trees can ensure that size of sampled figs is similar. Once they matured, we counted the number of wasp offspring, viable seeds and vacant female flowers. Similar counts were made from mature figs under natural conditions from four sample sites where non-pollinators had been allowed to oviposit, and each sample site at least contain four trees. The number of wasp offspring, viable seeds and vacant female flowers were also collected under the natural conditions from three kinds of habitat sites: primary forest; locally fragmented forest, where fig trees still occur in groups; and highly fragmented forest, in which fig trees are isolated in distribution.

The pollination and oviposition efficiency of foundresses might greatly affect the trade-off between the figs and pol- linators wasps $[22,28,29]$. We also examined whether the pollination and oviposition efficiency of foundresses varies seasonally. Figs pollinated by a single foundress often abort [30,31], and interference competition for pollination or oviposition between foundresses is not significant in large figs (e.g., those of F. racemosa) when foundress number is two [10]. The mean pollination and oviposition per foundress for syconia containing two foundresses can therefore be used to evaluate oviposition efficiency of foundresses. We conducted such experiments in both the warm and cold seasons.

All of the above data of the number of wasp offspring, viable seeds and vacant female flowers of figs are sampled at late ' $C$ phase', when the figs contain almost mature seeds, and larvae/pupae. Galled flowers, viable seeds and vacant female flowers were counted. At this stage seeds and galls are easily distinguished and the numbers of foundresses that had entered can be counted (the foundresses do not re-emerge from the figs). Fig diameter can also be reliably measured, because the figs are still firm. We cut each fig vertically into eight slices passing through the ostiole, and then haphazardly selected two or three slices to sample all the galls, seeds and vacant flowers present. The galls and seeds (but not vacant flowers) in the rest of the fig were also counted. The proportions of seeds and galls did not differ significantly between pairs of slices from the same figs $(t=0.25, \mathrm{~d} f=38, P>0.05)$ suggesting a homogeneous distribution of galls and seeds. This allowed us to calculate the percentage of developed flowers (galls+seeds) per fig and to estimate the total number of female flowers per fig using the following calculation: total number of female flowers $=$ (total galls+total seeds)/proportion of developed flowers.

\subsection{Loss of attraction to pollinators}

The pollinator wasps enter the central lumen of the receptive fruits through the ostiole consistence of bracts, and the fig will enclose the ostiole properly after the pollinator wasps entering the syconium cavity, and our previous experiment showed that the ostiole closure will be a density dependent process as a function of foundress number [29]. In these experiments, we will examine whether the ostiole closure of fig will differ between seasons. In warm season of April to May and cold season of December to January, when the fruits become receptive, all of the fruits were assigned one of the three treatment levels: the experimental introduction of three or nine foundresses, which had been first caught with an insect net from the near trees. In one treatment, keep the receptive syconia free of foundresses.

After the introduction of the foundresses, we placed one further female next to the ostiole. If she attempted to enter she was removed and the process was repeated and observe the wasp will enter the ostiole. If the wasp partly entered into the ostiole, we immediately dragged the wasp out the ostiole. If the wasp cannot enter the ostiole, the time was 
counted as the onset ostiole closure. Such one wasp examination on whether the ostioles are enclosed was carried every $4 \mathrm{~h}$ in the time that ostioles have not begun to enclose, but was carried every $1 \mathrm{~h}$ when the ostioles begin to enclose. This rough estimation on how long the ostiole will be enclosed after the foundress is introduced into the fig cavity is based on the previous observation or experiment results [29].

\section{Results}

The stigmas of $F$. racemosa form a roughly even stigma that lines the cavity at the centre of receptive figs. Style lengths in receptive fruits were unimodal in distribution (Figure 1A), whereas the pedicels of the female flowers were strongly left skewed (Figure 1B). Pedicel length was negatively correlated with style length $(N=325, r=-0.48$, $P<0.001)$. Pedicel lengths in mature figs were longer than that in receptive figs $(t=35.5, \mathrm{~d} f=1536, P<0.001$; receptive: $0.46 \pm 0.41 \mathrm{~mm}, N=325$; mature: $2.90 \pm 1.21 \mathrm{~mm}, N=1213$; Figure 1) but were still negatively correlated with style lengths at that time $(N=1213 ; r=-0.59, P<0.001)$. The pedicel lengths of galls were longer than that of seeds in mature figs $(t=27.1, \mathrm{~d} f=1211, P<0.001$, seed: $2.0 \pm 0.49 \mathrm{~mm}, N=515$; gall: $3.5 \pm 1.19 \mathrm{~mm}, N=698$ ), indicating either that wasp larvae stimulate the growth of pedicels or that females prefer to oviposit into flowers presenting long pedicels.

Styles of flowers that gave rise to galls were significantly shorter than were those with seeds $(t=30.2, \mathrm{~d} f=1211$, $P<0.001$; seed: $2.03 \pm 0.49 \mathrm{~mm}, N=515$; gall: $1.27 \pm 0.39 \mathrm{~mm}$, $N=698$ ). Some galls developed from flowers with longer styles than the longest recorded ovipositor length (Figure
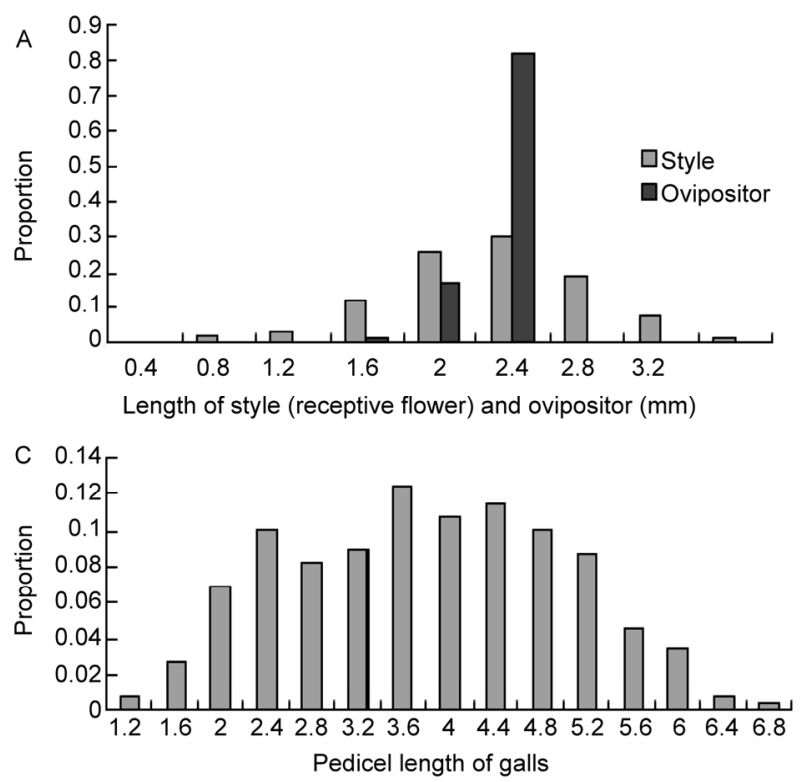

1D). Ovipositor lengths largely overlapped with style lengths of flowers in receptive figs, showing that only a small part of styles were immune from oviposition by even the largest foundresses (Figure 1A; $t=0.04, \mathrm{~d} f=504$, n.s.). Therefore, style length is not causal factor explaining the abundance of unexploited flowers. We found higher production of galls in the cold season (Figure 2), with up to $60 \%$ of female flowers giving rise to galls, which confirms previous observations that pollinators can oviposit in most female flowers in both Ficus sycomorus [22,32] and other figs [11].

The seed and gall numbers in the figs differed greatly between warm and cold seasons. In the warmer months, the proportion of undeveloped female flowers was high (Figure $2 \mathrm{E}$ ) and both seed and gall proportions reached an asymptote with increasing numbers of foundresses (Figure 2A and C). In the cold season, however, seed production decreased from an intermediate optimum number of foundresses in the syconium and gall production did not change with changing foundress numbers (Figure $2 \mathrm{~B}$ and D). More foundresses in the syconium cavities led to a decrease in seed production in the cold season when there were no more vacant female flowers available (U-shaped, $F$ test $=5.39, P$-value $=0.006$ ).

The average offspring number per foundress was lower in the warmer months. Experimental introduction of two foundresses per receptive syconium revealed an average offspring number per foundress in a warm month (September) of $307.5 \pm 136.4(N=12)$ and in the cold month of November of $1099.4 \pm 319.2(N=13) ;(t=8.3, \mathrm{~d} f=25, P<0.001)$. Pollination efficiency per foundress was also greater in the cold season, with a foundress generating on average $663.7 \pm 208.2(N=13)$ viable seeds in November and $490.2 \pm 223.6(N=12)$ in the warm season (September) $(t=2.1$,
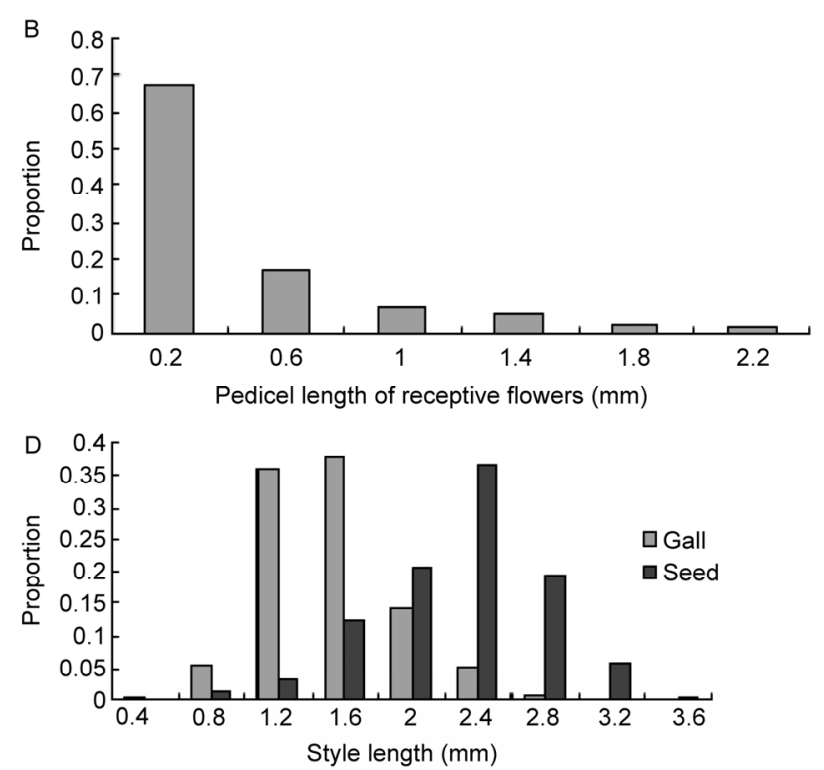

Figure 1 Frequency distribution of (A) style length of receptive flowers $(N=325)$ and ovipositor length of the pollinator $C$. fusciceps $(N=181)$, (B) pedicel length of receptive flowers $(N=325)$, (C) pedicel length of galls $(N=698)$ in mature syconia and (D) style length of flowers that gave rise to seeds $(N=515)$ or wasp galls $(N=698)$ in mature syconia. 

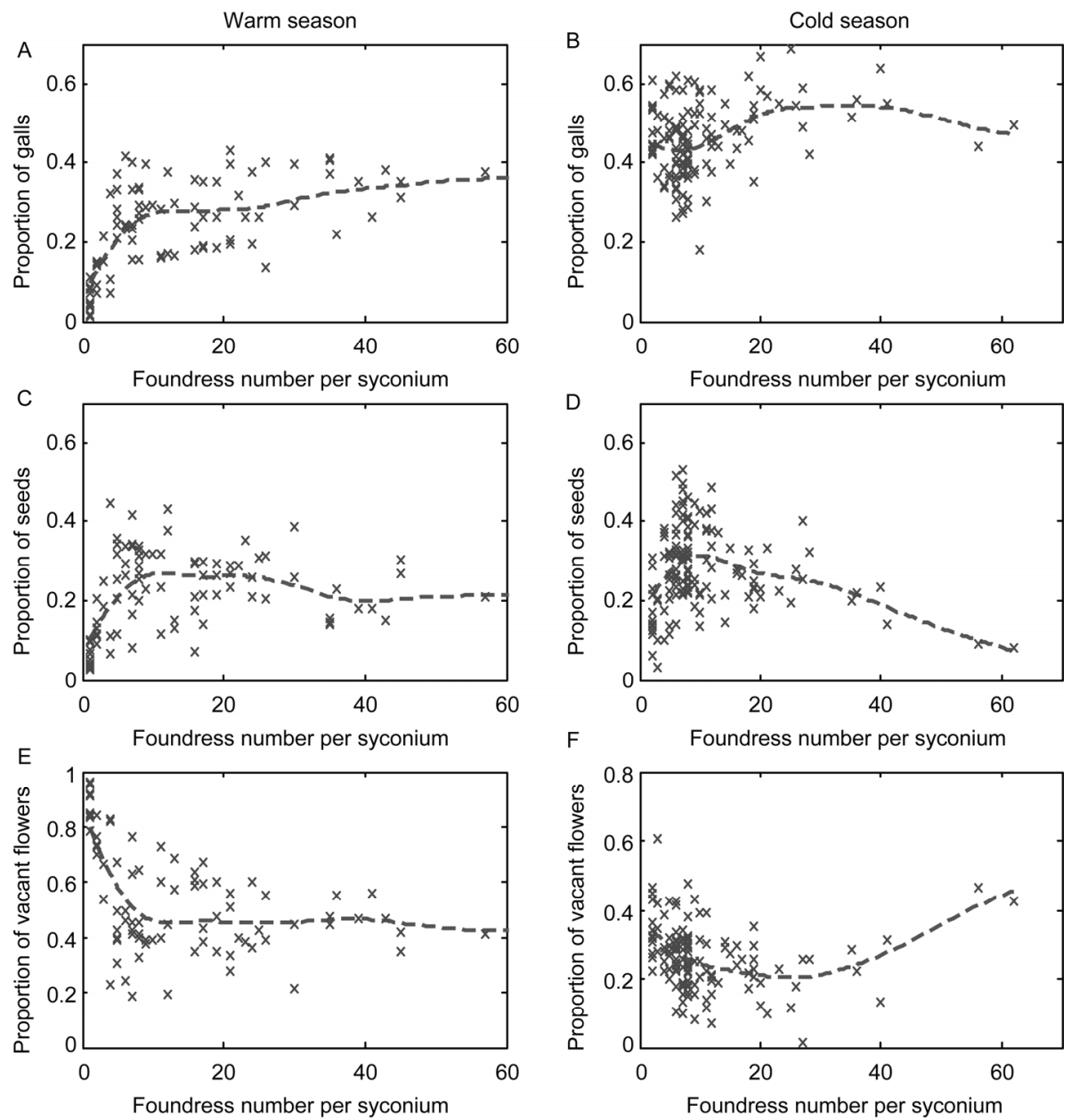

Figure 2 The proportion of seeds, galls and vacant female flowers as a function of foundress number during the warm season and the cold season. The syconia were enclosed in nylon gauze except during the receptive period to exclude non-pollinators. $N=75$ in the cold season (Nov-Jan). $N=65$ in the warm season (May-Sep).

Table 1 Contents of figs from late $C$ phase crops collected in the cold and warm seasons at XTBG (mean \pm SE), and the relationships between pollinator offspring numbers in the figs and foundress numbers ${ }^{\text {a) }}$

\begin{tabular}{|c|c|c|c|c|c|c|c|c|}
\hline $\begin{array}{l}\text { Tree No. } \\
\text { (Habitat) }\end{array}$ & Crop No. & Season & $N$ (Figs) & $\begin{array}{c}\text { Foundress } \\
\text { numbers }\end{array}$ & $\begin{array}{l}\text { Offspring/ } \\
\text { foundress }\end{array}$ & Total flowers & $\begin{array}{c}\text { Vacant flowers } \\
(\%)\end{array}$ & Coefficient $(r)$ \\
\hline \multirow[t]{3}{*}{1 (HFA) } & 1 & Warm & 18 & $10.33 \pm 1.2$ & $205 \pm 73$ & $6734 \pm 188$ & $41.3 \pm 1.0$ & $0.72^{* * *}$ \\
\hline & $2 a$ & Cold & 14 & $8.6 \pm 1.0$ & $461 \pm 153$ & $7227 \pm 159$ & $26.8 \pm 1.0$ & -0.18 \\
\hline & $2 b^{*}$ & Cold & 26 & $10.8 \pm 2.1$ & $586 \pm 515$ & $5738 \pm 149$ & $27.8 \pm 2.0$ & $-0.65^{* * *}$ \\
\hline \multirow[t]{2}{*}{$2(\mathrm{PF})$} & 1 & Warm & 23 & $18.8 \pm 2.9$ & $261 \pm 213$ & $8305 \pm 278$ & $47.6 \pm 3.0$ & $0.74^{* * *}$ \\
\hline & 2 & Cold & 21 & $20.2 \pm 5.0$ & $603 \pm 729$ & $5737 \pm 791$ & $21.1 \pm 2.6$ & $-0.79^{* * *}$ \\
\hline \multirow[t]{2}{*}{4 (LFP) } & 1 & Warm & 41 & $11.2 \pm 1.0$ & $160 \pm 111$ & $7218 \pm 360$ & $54.2 \pm 2.3$ & $0.61^{* * *}$ \\
\hline & 2 & Cold & 24 & $8.3 \pm 3.5$ & $390 \pm 152$ & $7281 \pm 975$ & $30.3 \pm 7.5$ & $-0.51^{* *}$ \\
\hline
\end{tabular}

a) *, $P<0.05$; **, $P<0.01$; ***, $P<0.01$. TFF, total number of female flowers per fruit; VFF, number of vacant female flowers per fruit. The sampled tree is in the local fragmented forest. Non-pollinators were only excluded from crop $2 b^{*}$.

$\mathrm{d} f=25, P<0.05)$. This left fewer vacant female flowers in the cold season than in the warm across the range of variation in number of foundresses (Figure 2). Furthermore, in the cold season we found a clear negative relationship between flowers utilized for wasp reproduction versus seed reproduction for most crops examined but in the warm season the relationship was uniformly positive (Figure 3 , Table 1 ).

Table 2 shows that fruit size, number of vacant female flowers, total female flowers and foundress number are correlated significantly with the production of viable seeds and wasp galls for some crops but not for others. Foundress number per syconium also increased with fruit size $(N=93$, 
Table 2 Effects of fruit size (diameter), foundress number, total number of female flowers and vacant female flowers on the production of viable seeds and wasp offspring (galls) of the same tree in F. racemosa at different crops (by Pearson correlation) ${ }^{\text {a) }}$

\begin{tabular}{|c|c|c|c|c|c|c|c|c|c|}
\hline \multirow[b]{2}{*}{ Sample date } & \multirow[b]{2}{*}{$N$ (figs) } & \multicolumn{4}{|c|}{ Galls versus } & \multicolumn{4}{|c|}{ Seeds versus } \\
\hline & & $\begin{array}{c}\text { Foundress } \\
\text { No. }\end{array}$ & Fig Diam. & Vacant flowers & $\begin{array}{l}\text { Total female } \\
\text { flowers }\end{array}$ & $\begin{array}{c}\text { Foundress } \\
\text { No. }\end{array}$ & Fig Diam. & Vacant flowers & $\begin{array}{l}\text { Total female } \\
\text { flowers }\end{array}$ \\
\hline Jan & 16 & $0.75^{* * *}$ & $0.77^{* * * *}$ & $0.15 \mathrm{~ns}$ & $0.66^{*}$ & $-0.46^{*}$ & $0.43 \mathrm{~ns}$ & $-0.12 \mathrm{~ns}$ & $0.59^{* *}$ \\
\hline May & 20 & $0.79^{* * * *}$ & $0.78^{* * * *}$ & $-0.17 \mathrm{~ns}$ & $0.45^{*}$ & $-0.29 \mathrm{~ns}$ & $-0.20 \mathrm{~ns}$ & $0.01 \mathrm{~ns}$ & $0.4 \mathrm{~ns}$ \\
\hline Sep & 18 & $-0.26 \mathrm{~ns}$ & $0.78^{* * * *}$ & $0.06 \mathrm{~ns}$ & $0.73^{* * * *}$ & $-010 \mathrm{~ns}$ & $0.89^{* * *}$ & $0.11 \mathrm{~ns}$ & $0.81^{* * *}$ \\
\hline Nov & 20 & $0.37 \mathrm{~ns}$ & $-0.14 \mathrm{~ns}$ & $-0.51^{*}$ & $0.09 \mathrm{~ns}$ & $-0.15 \mathrm{~ns}$ & $0.69^{* *}$ & $0.43^{*}$ & $0.64^{* * *}$ \\
\hline
\end{tabular}

a) ${ }^{*}, P<0.05$; **, $P<0.01$; ***, $P<0.01$; ns is not significant at $P=0.05$. TFF, total number of female flowers per fruit; VFF, number of vacant female flowers per fruit. The sampled tree is in the local fragmented forest.
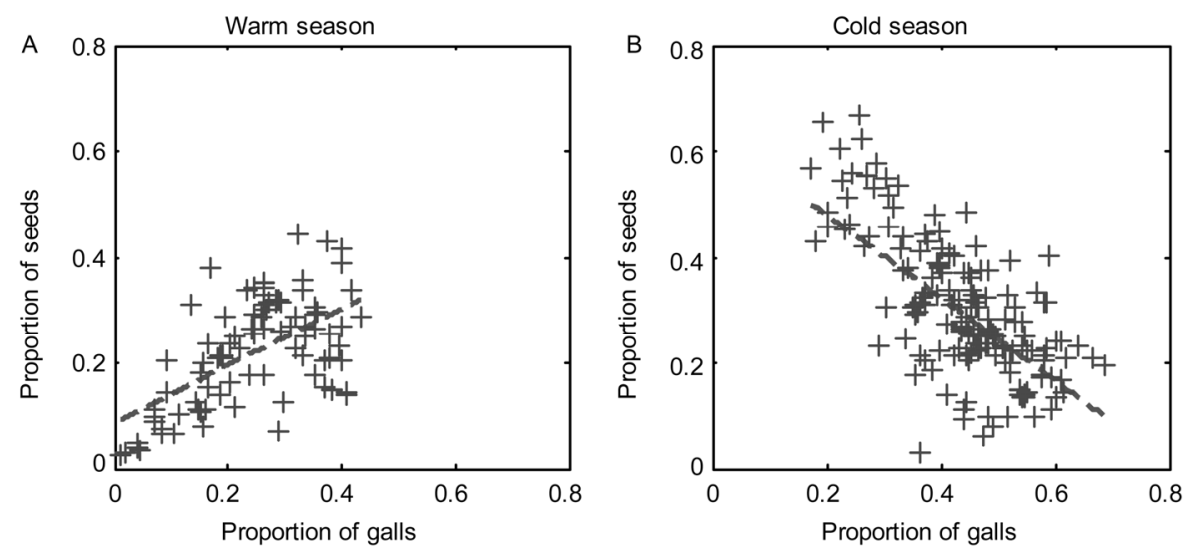

Figure 3 The relationship between proportion of seeds and proportion of gall number in (A) the warm ( $N=107)$ and (B) the cold season ( $N=159)$. Including data collected under natural conditions.

$r=0.68, P<0.001$ after controlling for crops and sample sites). The impact of these ecological factors essentially affect the trade-off between figs and fig wasps through the offspring production of the fig wasps, viable seed production of figs and the availability of female flowers (vacant female flowers). Tables 1 and 2 indicate that ecological factors can significantly affect both figs and fig wasps' fitness and thereby also significantly affecting the trade-off between these partners.

The fig can wait for the pollinators entering their syconium cavities if there are no pollinator wasps in their syconium cavities or the foundress number is too low, but the fig will enclose their syconium quickly if their syconium already has a high number of foundresses (Figure 4, also see [29]). The quick closure of osiole will prevent the extra more pollinator wasps from entering the syconium cavities and/or from exiting the syconium cavities after pollinators entering lumen, which will create the intensive interference competition among the foundresses in their egg preposition [16]. The experiment here also showed that in the cold season, the ostiole closure will be much slower than that in the warm season after the foundress entering into the syconium cavities. If there is no foundress entering their syconium cavities, the fig will also wait for a much longer time in the cold season than in the warm season.



Figure 4 Ostiole closure in syconia with different numbers of simultaneously introduced foundresses in different seasons. The ostiole closes more quickly when more foundresses are introduced. In all of the three treatments, the ostiole closes more quickly in the warm season than in cold season. Sample size $N$ in each treatment $>22$.

\section{Discussion}

Theoretical analyses show that a conflict can exist in reciprocal mutualisms [33-36]. Thus which mechanisms prevent direct conflict between reciprocal mutualists and maintain the cooperation stable is controversial [21,37-39]. Hypoth- 
eses for explaining the stability of the fig-fig wasp mutualism argue that overexploitation of fig flowers is precluded by the long style and/or pedicel and other structural barriers together with either a short ovipositor length or insufficient eggs of the pollinator wasps. However, none of these potential barriers is sufficient to explain fig/fig wasp mutualism stability [11,12,17,22,29,39-41]. Although structural constraints, such as long styles of fig flowers could be barrier for the pollinators to over-exploit flowers at the expense of seeds of figs, we revealed direct conflict between $F$. racemosa and its pollinating wasps during the cold season, which imply that either structural barriers or short ovipositor length or insufficient eggs of the pollinator wasps are insufficient for maintaining the stability of fig/fig wasp mutualism.

Our results showed that the fitness interaction varies across seasonal time or environmental change, similar to the findings that fitness interaction between reciprocal mutualists might oscillate between mutualism and antagonism across time or spatial variability [22,42-44]. Our data in fig/fig wasp mutualism further presented that antagonism (negative fitness correlation) between wasp offspring (galls) and viable seeds in the cold season might be because female flowers were saturated during this period, at least at moderate foundress numbers (Figure 2). However, vacant female flower numbers increased at high foundress numbers in the cold season, being best described by the following U-shaped function: vacant female flower number $y=0.03134-0.0079 n+0.0002 n^{2}$ ( $n=$ foundress number). $F(1$, error) $=10.54, P=0.0016$ for the negative linear coefficient and $F(1$, error $)=15.72, P=0.0001$ for the positive quadratic coefficient. When female flowers are saturated, as was the case at moderate foundress numbers, additional wasp larvae can only be produced at the expense of viable seeds. At high foundress numbers, even though more vacant female flowers persisted, fewer viable seeds were produced for similar proportions of galled flowers (Figure 2).

In the warm season, on the other hand, female flowers were never saturated, either because of interference among foundresses or their brief lifespans $[39,45]$. The different nature of the relationship between fitness of figs and fig wasps between the seasons was not due to a difference in floral structure, since experimental sequential introduction of multiple foundresses allowed the saturation of female flowers even in the warm season. The interference among foundresses that appeared to be particularly pronounced at high foundress numbers, will further aggravate the difficulty in finding empty flowers, and can prevent egg deposition and pollen dispersal of foundress even when vacant flowers are still plentiful [39], particularly if foundress lifespans are very short as is the case during the warm season [15]. Hence, based on our observations we suggest that the fig/fig wasp mutualism can be stabilized by seasonal heterogeneity in foundress lifespan and hence oviposition and pollination efficiency in part due to different regimes of interference among foundresses within synconia.

Short foundress lifespans and interference, which prevent saturation of female flowers in the warm season and hence generate the positive relationship between the fitness of figs and fig wasps, is vulnerable because short foundress lifespans can be compensated by increased foundress numbers and interference among the foundresses can be prevented by longer intervals between entry of individual foundresses. The optimization of foundress number by the figs, which was hypothesized by Herre [46], might be most critical for maintaining this fig/fig wasp mutualism. Allowing more foundresses to enter by maintaining the ostiole open for longer can increase the fig's fitness when vacant female flowers are plentiful (Figures 2 and 3), as has been suggested or observed by many field scientists [2,29,46-48]. On the other hand, preventing entry of additional foundresses by closing the ostioles can prevent over-exploitation of female flowers at the expense of the viable seeds. This can preclude the breakdown of cooperation between figs and fig wasps $[44,49]$. A controlled experiment shows that figs close their ostiole rapidly if many foundresses enter a syconium but keep it open when foundress numbers are low [29]. This suggests that figs detect and respond to foundress numbers, preventing the presence of too many foundresses in the syconia and thereby the conflict between the figs and fig wasps rather than relying on intrinsic features of the figs or evolutionary-restraint of the pollinators.

It has been shown that genetic relatedness alone might be insufficient for maintaining the stable cooperation [36,50], and that repression or policing is also required in the evolution of cooperation [50-52]. The necessity of repression or punishment of cheaters or competitors that take food or service without reciprocal reward was widely proven in previous studies [30,53,54]. However, an overabundance of cooperative partners can also result in an extra cost to recipients after the commons are saturated such that no additional reward can be gained [55-58]. Our data on the fig/fig wasp mutualism show that more foundresses in the syconia did not increase viable seed production but rather decreased it when vacant female flowers remained limited. We therefore highlight that repression to the number of the cooperative partners will also be required in the evolution of cooperation, similar to repression or policing of cheating.

Although our data showed that temporal heterogeneity is important in the fig/fig wasp mutualism stability, the parasites of mutualism might also directly or indirectly affect the fitness interaction between reciprocal mutualists $[4,42,57,59]$. Non-pollinators of gall makers in fig/fig wasp mutualism could independently oviposit in the female flowers of $F$. racemosa and thereby impede both pollinator and viable seed production [23,25,26,40,59,60]. Gall and seed numbers may be greatly affected by non-pollinator oviposition in highly fragmented forests where non-pollinator density is much higher [16,25]. Our experiments in highly fragmented areas showed that viable seed numbers decline 
with increasing numbers of wasp offspring when we excluded non-pollinators in January but there was no relationship under natural conditions (Table 1). In the dry season the figs contain many more of the non-pollinators in the highly fragmented areas [15] and interference by non-pollinators might obscure the true functional relationship between the viable seeds and wasp offspring.

In $F$. racemosa the relationship between viable seed and the wasp offspring (gall) numbers differs greatly among different sites and crops. Style length or other structural traits of the female flowers, temperature, habitat sites, non-pollinators' interference and abundance of foundresses can directly affect the production of viable seeds and wasp offspring. Local variation in these factors can obviously affect the relationship between viable seed and wasp offspring production, so the fig and fig wasp interaction is conditional, as previously argued [4,44,61]. Essentially, the sign of the correlation between wasp offspring and viable seed production depends on the availability of female flowers in the absence of other confounding factors [41]. The cooperative interaction can turn into a conflictual one when cooperative partners are too numerous, i.e., $N>b / c$ ( $b$ is the benefit for cooperation, $c$ is the cost for cooperation), if spatial constraint is inadequate for preventing cooperative partners from overexploiting the commons at the expense of other involved partners $[56,58,62]$. In the fig/fig wasp mutualism, the trade-off between figs and fig wasps can be affected by the total number of female flowers and the proportion of those that are pollinated or parasitized [22,29,41]. This latter proportion is determined by foundress number and utilization efficiency of each foundress, which will be greatly affected by ecological factors including competition and interference within the syconium but also temperature and humidity. The trade-off between figs and their pollinator wasps can therefore be very easily obscured.

\section{Conclusion}

Our previous work has shown that interference competition among foundresses together with high temperature could favor the cooperative stability between fig and its pollinator wasps. Here we add that cooperation between fig and their pollinator wasps results from the un-saturation of a common resource (female flowers), whilst interference competition among foundresses and high temperature reduces common resource exploitation. The structural barrier and shortovipositor length of pollinator wasps might greatly affect the reproduction of the tree and its pollinator wasps but these two mechanisms are not alone able to maintain stability in cooperation between the mutualists. We found biological factors, such as non-pollinating fig wasps, seasonal variation, play a role in the reproductive trade-off between figs and pollinator wasps. Our experiments and observations imply that host repression through active regulation of osti- ole closure, which can create interference competition among the foundresses and prevent excessive numbers of foundresses entering figs, may play a large role in maintaining mutualism stability. This is analogous to repression or policing of cheating or overly competitive behaviors in other cooperative systems.

We are indebted to Jacqui A. Shykoff, Claire Maries, Mark Rausher, Edward Allen Herre, Derek Dunn, Stuart A West, Finn Kjellberg for their draft revision and discussion on this manuscript, and to Da-Rong Yang, Zhang-Hong Shi, Li-Feng Bai, Shu-Wei Zhai, Xiao-Kui Fan, Xiao-Bo Xie for their contribution in data collection. This work was supported by the National Natural Science Foundation of China (31170408, 31270433, 31370408), the National Science Fund for Distinguished Young Scholars (31325005), NSFC-Yunnan United Fund (U1302267), the West Light Foundation of the Chinese Academy of Sciences.

1 Anstett MC, Hossaert-McKey M, Kjellberg F. Figs and fig pollinators: evolutionary conflicts in a coevoled mutualism. Trends Ecol Evol, 1997, 12: 94-99

2 Herre EA, West SA. Conflict of interest in a mutualism: documenting the elusive fig wasp-seed trade-off. Proc R Soc B, 1997, 264: 1501-1507

3 Herre EA, Knowlton N, Mueller UG, Rehner SA. The evolution of mutualisms: exploring the paths between conflict and cooperation. Trends Ecol Evol, 1999, 14: 49-53

4 Bronstein JL. The costs of mutualism. Am Zool, 2001, 41: 825-839

5 HoeksemaJD, Schwartz MW. Expanding comparative-advantage biological market models: contingency of mutualism on partner's resource requirements and acquisition trade-offs. Proc R Soc B, 2003, 270: 913-919

6 Janzen DH. How to be a fig. Annu Rev Ecol Syst, 1979, 10: 13-51

7 Wiebes J. Co-evolution of figs and their insect pollinators.Annu. Rev Ecol Syst, 1979, 10: 1-12

8 Murray M. Figs (Ficus spp.) and fig wasps (Chalcidoidea, Agaonidae): hypotheses for an ancient symbiosis. Biol J Linn Soc, 1985, 26 : 69-81

9 Grafen A, Godfray H. Vicarious selection explains some paradoxes in dioecious fig-pollinator systems. Proc R Soc B, 1991, 245: 73-76

10 Bronstein JL. Mutualism, antagonism, and the fig-pollinator interaction. Ecology, 1988, 69: 1298-1302

11 Nefdt RJ, Compton SG. Regulation of seed and pollinator production in the fig-fig wasp mutualism. J Anim Ecol, 1996, 170-182

12 Kathuria P, Ganeshaiah K, Uma Shaanker, Vasudeva R. Is there dimorphism for style lengths in monoecious figs? Curr Sci India, 1995, 68: 1047-1049

13 Anstett MC. Unbeatable strategy, constraint and coevolution, or how to resolve evolutionary conflicts: the case of the fig/wasp mutualism. Oikos, 2001, 95: 476-484

14 West SA, Herre EA. The ecology of the New World fig-parasitizing wasps Idarnes and implications for the evolution of the fig-pollinator mutualism. Proc R Soc B, 1994b, 258: 67-72

15 Wang RW, Yang JX, Yang DR. Seasonal changes in the trade-off among fig-supported wasps and viable seeds in figs and their evolutionary implications. J Integr Plant Biol, 2005a, 47: 144-152

16 Wang RW, Sun BF. Seasonal change in the structure of fig-wasp community and its implication for conservation. Symbiosis , 2009, 47 77-83

17 Anstett MC. Unbeatable strategy, constraint and coevolution, or how to resolve evolutionary conflicts: the case of the fig/wasp mutualism. Oikos, 2001, 95: 476-484

18 Compton S, Nefdt R. The figs and fig wasps of Ficus burtt-davyi. Mitt Inst Allg Bot Hamburg, 1990, 23: 441-450

19 Jousselin E, Hossaert-Mckey M, Vernet D, Kjellberg F. Egg deposition patterns of fig pollinating wasps: implications for studies on the 
stability of the mutualism. Ecol Entomol, 2001, 26: 602-608

20 Dunn DW, Jansen-González S, Cook JM, Yu DW, Pereira RAS. Measuring the discrepancy between fecundity and lifetime reproductive success in a pollinating fig wasp. Entomol Exp Appl, 2011, 140: 218-225

21 Bronstein JL, Hossaert-McKey M. Variation in reproductive success within a subtropical fig/pollinator mutualism. J Biogeogr, 1996, 23: 433-446

22 Wang RW, Sun BF, Zheng Q, Shi L, Zhu LX. Asymmetric interaction and indeterminate fitness correlation between cooperative partners in the fig-fig wasp mutualism. J R Soc Interface, 2011, 8: 1487-1496

23 Kerdelhue C, Rossi JP, Rasplus JY. Comparative community ecology studies on old world figs and fig wasps. Ecology, 2000, 81: 2832-2849

24 Corner EJH. Check-list of Ficus in Asia and Australasia with keys to identification. Gard Bull Singap, 1965, 21: 1-186

25 Wang RW, Yang CY, Zhao GF, Yang JX. Fragmentation effects on diversity of wasp community and its impact on fig/fig wasp interaction in Ficus racemosa. L J Integr Plant Biol, 2005, 47: 20-26

26 Yang DR, Zhao TZ, Wang RW, Zhang GM, Song QS. Study on pollination ecology of fig wasp (Ceratosolen $\mathrm{sp}$.) in the tropical rainforest of Xishuangbanna, China. Zool Res, 2001, 22: 125-130

27 Zhang FP, Peng YQ, Compton SG, Yang DR. Floral Characteristics of Ficus curtipes and the oviposition behavior of its pollinator fig wasp. Ann Entomol Soc Am, 2009, 102: 556-559

28 Dunn DW, Yu DW, Ridley J, Cook JM. Longevity, early emergence and body size in a pollinating fig wasp-implications for stability in a fig-pollinator mutualism. J Anim Ecol, 2008, 77: 927-935

29 Wang RW, Ridley J, Sun BF, Zheng Q, Dunn DW, Cook J, Shi L, Zhang YP, Douglas WY. Interference competition and high temperatures reduce the virulence of fig wasps and stabilize a fig-wasp mutualism. PLoS One, 2009, 4: e7802

30 Wang RW, Sun BF, Zheng Q. Diffusive coevolution and mutualism maintenance mechanisms in a fig-fig wasp system. Ecology, 2010, 91: 1308-1316

31 Wang RW, Dun DW, Sun BF. Discriminative sanction in fig-fig wasp mutualism. Ecology, 2014, 95: 1384-1393

32 Galil J, Eisikowitch D. Studies on mutualistic symbiosis between syconia and sycophilous wasps in monoecious figs. New Phytol, 1971, 70: 773-787

33 Axelrod R, Hamilton WD. The evolution of cooperation. Science, 1981, 211: 1390-1396

34 Pellmyr O, Huth CJ. Evolutionary stability of mutualism between yuccas and yucca moths. Nature, 1994, 372: 257-260

35 Pellmyr O, Leebens-Mack J. Reversal of mutualism as a mechanism for adaptive radiation in yucca moths. Am Nat, 2000, 156: S62-76

36 West SA, Pen I, Griffin AS. Cooperation and competition between relatives. Science, 2002b, 296: 72-75

37 Bronstein J. Seed predators as mutualists: ecology and evolution of the fig/pollinator interaction. Insect-Plant Interact, 1992, 4: 1-44

38 Hoeksema JD, Bruna EM. Pursuing the big questions about interspecific mutualism: a review of theoretical approaches. Oecologia, 2000, 125: 321-330

39 Yu DW, Ridley J, Jousselin E, Herre EA, Compton SG, Cook JM, Moore JC, Weiblen GD. Oviposition strategies, host coercion and the stable exploitation of figs by wasps. Proc R Soc B, 2004, 271: 1185-1195

40 West SA, Herre EA. The ecology of the New World fig-parasitizing wasps Idarnes and implications for the evolution of the fig-pollinator mutualism. Proc R Soc B, 1994a, 258: 67-72

41 Wang RW, Shi L, Ai SM, Zheng Q. Trade-off between reciprocal mutualists: local resource availability-oriented interaction in fig/fig wasp mutualism. J Anim Ecol, 2008, 77: 616-623

42 Morris WF, Wilson WG, Bronstein JL, Ness JH. Environmental forcing and the competitive dynamics of a guild of cactus-tending ant mutualists. Ecology, 2005, 86: 3190-3199

43 Ness J, Morris W, Bronstein J. Integrating quality and quantity of mutualistic service to contrast ant species protecting Ferocactus wislizeni. Ecology, 2006, 87: 912-921

44 Piculell B, Hoeksema J, Thompson J. Interactions of biotic and abiotic environmental factors in an ectomycorrhizal symbiosis, and the potential for selection mosaics. BMC, 2008, 6: 23

45 Wang RW, Yang JX, Yang DR. Seasonal changes in the trade-off among fig-supported wasps and viable seeds in figs and their evolutionary implications. J Integr Plant Biol, 2005c, 47: 144-152

46 Herre EA. Coevolution of reproductive characteristics in 12 species of New World figs and their pollinator wasps. Experientia, 1989, 45: 637-647

47 Khadari B, Gibernau M, Anstett MC, Kjellberg F, Hossaert-McKey M. When figs wait for pollinators: the length of fig receptivity. Am J Bot, 1995, 992-999

48 Anstett MC, Kjellberg F, Bronstein JL. Waiting for wasps: consequences for the pollination dynamics of Ficus pertusa L. J Biogeogr, 1996, 23: 459-466

49 Liu C, Yang DR, Compton SG, Peng YQ. Larger fig wasps are more careful about which figs to enter-with good reason. PLoS One, 2013, 8: e74117

50 Clutton-Brock T. Breeding together: kin selection and mutualism in cooperative vertebrates. Science, 2002, 296: 69-72

51 Clutton-Brock TH, Parker GA. Punishment in animal societies. Nature, 1995, 373: 209-216

52 Frank SA. Mutual policing and repression of competition in the evolution of cooperative groups. Nature, 1995, 377: 520-522

53 Kiers ET, Rousseau RA, West SA, Denison RF. Host sanctions and the legume-rhizobium mutualism. Nature, 2003, 425: 78-81

54 Jander KC, Herre EA, Simms EL. Precision of host sanctions in the fig tree-fig wasp mutualism: consequences for uncooperative symbionts. Ecol Lett, 2012, 15: 1362-1369

55 Queller DC. Does population viscosity promote kin selection? Trends Ecol Evol, 1992, 7: 322-324

56 Taylor P. Altruism in viscous populations-an inclusive fitness model. Evol Ecol, 1992, 6: 352-356

57 Wilson DS, Pollock G, Dugatkin LA. Can altruism evolve in purely viscous populations? Evol Ecol, 1992, 6: 331-341

58 Queller DC. Genetic relatedness in viscous populations. Evol Ecol, 1994, 8: 70-73

59 Morris WF, Bronstein JL, Wilson WG. Three-way coexistence in obligate mutualist-exploiter interactions: the potential role of competition. Am Nat, 2003, 161: 860-875

60 Yang CY, Wang RW, Zhao GF ,Yang DR. Diet of non-pollinator wasp and its impact on the fig-pollinator wasp mutualism. Zool Res, 2005, 26: 379-385

61 Bronstein JL. Conditional outcomes in mutualistic interactions. Trends Ecol Evol, 1994, 9: 214-217

62 West S, Kiers ET, Pen I, Denison R. Sanctions and mutualism stability: when should less beneficial mutualists be tolerated? J Evol Biol, 2002a, 15: 830-837

Open Access This article is distributed under the terms of the Creative Commons Attribution License which permits any use, distribution, and reproduction in any medium, provided the original author(s) and source are credited. 